\title{
GOFFMAN E AS RELAÇÕES DE PODER NA VIDA COTIDIANA*
}

\section{Édison Gastaldo}

\section{Introdução}

A obra de Erving Goffman ainda é muito pouco explorada nas ciências sociais brasileiras, mesmo que reconheçamos a ampla difusão de seus três principais livros, $A$ representação do eu na vida cotidiana (1975), Estigma (1975) e Manicômios, prisões e conventos (1974), entre estudantes e pesquisadores das ciências sociais, psicologia, serviço social, lingüística, educação e até mesmo administração de empresas. Além desses três livros (internacional-

* Uma versão preliminar deste artigo foi apresentada na XXXI Reunião da Anpocs, na mesa-redonda "Erving Goffman e as ciências sociais', organizada pelo prof. Carlos Benedito Martins (UnB). Agradeço a ele e ao prof. Gilberto Velho, pela interlocução, e a Soraia Teodoro da Silva, pela transcrição da apresentação, que serviu de base para este texto.

Artigo recebido em maio/ 2008

Aprovado em julho/2008 mente conhecidos como "the big three"), existem em português alguns artigos esparsos, publicados em coletâneas (como Riley e Nelson, 1976; Ribeiro e Garcez, 1998), além de dois livros sobre sua obra (Winkin, 1998, que inclui uma série de traduções de artigos inéditos em português, e Gastaldo, 2004). Ressalto a relativamente pequena exploração da obra de Goffman na academia brasileira porque mesmo que seus trabalhos sejam muito citados, eles o são apenas a partir de poucas temáticas, em geral de modo restrito, como a metáfora dramatúrgica, a noção de "instituição total" ou a situação de "estigma" que define os deficientes físicos.

Quando a obra de Goffman se tornou conhecida no Brasil, entre o final dos anos de 1960 e meados da década seguinte, o país vivia um momento de extrema repressão política e radicalização teórica nas ciências sociais (Velho, 2004), que aliava ortodoxia marxista à rejeição sistemática da literatura de origem norte-americana, considerada 
"meramente empiricista" e pouco comprometida com questões políticas, e com o que deveriam ser as "verdadeiras" preocupações da sociologia. Assim, por muito tempo, a obra de Goffman permaneceu à margem das vertentes principais da ciência social brasileira, classificada, não sem desdém, como "microssociologia". Tenho certa resistência com este termo: "micro" significa "menor", e as coisas "menores" são normalmente consideradas menos importantes do que as coisas "maiores", "macro", e esta valoração atribuída ao âmbito das abordagens sociológicas é, em minha opinião, equivocada. Assim, o objetivo deste texto é rever a obra de Goffman a partir de uma perspectiva política, evidenciando o modo pelo qual ele aborda a dinâmica das relações de poder na vida cotidiana. Apesar de tratar da obra de Goffman como um todo, deter-me-ei em dois de seus livros, escritos em momentos bastante diferentes de sua carreira: The presentation of self in everyday life, de 1959, e Gender advertisements, de 1979.

\section{A "representação do eu" e as políticas do cotidiano}

The presentation of self in everyday life foi o primeiro livro de Goffman, publicado a partir de sua tese de doutorado defendida na Universidade de Chicago (Communication conducts in an Island community, de 1953). O livro foi um sucesso de vendas desde sua primeira edição, vendeu mais de dois milhões de exemplares e foi traduzido em dezessete idiomas. No Brasil, é reeditado ininterruptamente desde 1975, sendo que em 2005 já alcançava sua 13a edição. Considero o título que o livro ganhou em português - A representação do eu na vida cotidiana uma má tradução: presentation é "apresentação", e não "representação"; self é um conceito central na teoria sociológica de Chicago, e, além da difícil tradução, é normalmente utilizado no original. Assim, se fizéssemos uma backtranslation do título, como sugeriu Andrew Carlin (2004), teríamos The representation of myself in everyday life, o que não faz sentido.

Deste livro, gostaria de destacar dois pontos para discussão. Em primeiro lugar, a noção de "definição da situação". Central no pensamento goffmaniano e de toda a Escola de Chicago, essa expressão é originária da obra de William Thomas, tendo aparecido pela primeira vez em um artigo de 1923. Trata-se do processo a partir do qual se atribui um sentido ao contexto vivido, da resposta que cada pessoa dá à seguinte pergunta: o que está acontecendo aqui, agora? Ela é central, portanto, para se compreender o modo como as pessoas orientam suas ações na vida cotidiana.

Por exemplo, se uma pessoa entra numa sala, vê um caixão com um corpo, velas, flores e gente chorando, certamente poderia pensar de que se tratava de um velório, e que seria melhor não contar alguma piada. Ou seja, as pessoas definem uma situação, e a partir disso orientam-se para agir de maneira adequada. Isso não significa necessariamente que a definição esteja correta. Poderia, seguindo o exemplo, não ser uma cena real de velório, e o sujeito dentro do caixão era um ator, não um defunto. Em outras palavras, uma definição equivocada da situação poderia causar constrangimento. Definir a situação, pois, é fundamental para a vida de qualquer indivíduo que vive em sociedade, no sentido de entender o que está acontecendo e se alinhar adequadamente às diferentes situações.

Deste ângulo pode parecer que a noção de definição da situação seja uma prerrogativa individual, um processo mental. Cada um definiria a situação como melhor lhe aprouvesse. Mas existem diferentes maneiras de definir uma mesma situação, e elas estão permeadas por uma relação de poder. Quem tem o poder de definir mais legitimamente o que está acontecendo ou, numa dimensão mais individual ainda, o que alguém "é"? Tomemos um exemplo trazido por Howard Becker:

Consideremos o caso da maconha. As pessoas que a usam têm uma linguagem para se referir a ela. Elas falam em "viajar", e têm muitos sinônimos para maconha, referindo-se a ela, por exemplo, como "marofa". [...] Outras pessoas, cujos mundos também incluem a maconha - médicos, advogados, policiais - terão outras palavras para as mesmas coisas, talvez falando de "adição", "cannabis", e "traficantes". [...] O modo pelo qual as coisas são chamadas quase sempre reflete relações de poder. As pessoas no poder chamam as coisas do que quiserem, e as outras têm que se ajustar a isso, talvez usando suas próprias palavras em privado, mas aceitando aquilo de que não podem escapar (2004, p. 102).

A relação de poder existe na medida em que algumas definições da situação são mais legítimas do que outras, e essa legitimidade é a resultante de quem tem o poder de propor e sustentar a definição. A diferença, por exemplo, entre um "militante 
de esquerda" e um "subversivo" - para pensar em categorias típicas da ditadura militar - é um questão de definição da situação.

Equívocos na definição da situação, por outro lado, podem se tornar questões de Estado. Goffman chama de "comunicação imprópria" a ação decorrente de uma definição equivocada da situação, quando alguém fala e faz coisas como se estivesse em um lugar apropriado. No início dos anos de 1990, por exemplo, o então todo-poderoso Ministro da Fazenda Rubens Ricupero conversava com um repórter, pouco antes de dar uma entrevista para a Rede Globo. Enquanto se ajustavam o foco e o microfone, as imagens iam sendo transmitidas por microondas para a unidade móvel, que enviaria o sinal "oficial" com a entrevista para todo o país. O que disse literalmente e entre sorrisos o ministro nos "bastidores"? Uma frase goffmaniana até a medula: "Eu não tenho escrúpulos: o que é bom, a gente mostra; o que é ruim, a gente esconde". Aconteceu que algumas antenas parabólicas de residências próximas ao local da entrevista captaram o sinal de microondas da câmera; algumas pessoas gravaram as imagens em videocassetes e as enviaram para emissoras de televisão. O estrago já estava feito. Não tem problema nenhum mostrar o que é bom e esconder o que é ruim, o problema é os outros ficarem sabendo que fazemos isso. Porque todos agem desta forma, "manejando a impressão", para usar uma expressão de Goffman. Mas se um ministro afirmar na frente de uma câmera para país inteiro ouvir que ele "não tem escrúpulos", sua posição torna-se insustentável. Ou seja, uma simples questão de controle da informação, por conta de uma definição equivocada da situação, mudou os rumos da economia nacional.

O que nos leva ao segundo ponto que gostaria de destacar: definindo mal a situação podemos nos expor a outra forma de poder bastante evocada ao longo de todo o livro - o poder do vexame, da vergonha, do embaraço, que é uma forma fundamental de coerção social. Trata-se de um resgate da categoria de "coerção social" discutida por Durkheim em As regras do método sociológico (2002). Apesar de tradicionalmente se pensar a coerção social como o poder de impor as leis (por multas, prisão ou violência "legítima"), Durkheim menciona nesta categoria a necessidade, por exemplo, de vestir roupas em público, pois o temor ao ridículo transforma-se em "punição indireta". Este é o ponto que Goffman (um durkheimiano confesso) desenvolve magistralmente. $\mathrm{Na}$ vida cotidiana, não necessitamos de soldados armados ou fiscais com talões de multa para irmos a lugares onde não queremos, conversarmos com pessoas de quem não gostamos ou falarmos coisas que não acreditamos. Por que agimos assim? Porque do contrário poderíamos "pagar um mico", dar vexame, passar vergonha, "perder a face" (Goffman, 1967). Goffman chama de "face" algo mais do que o rosto, toda a fachada que sustenta um indivíduo. $\mathrm{O}$ trabalho de face é o esforço que cada um de nós faz para manter-se à altura da dignidade que projetamos sobre nós mesmos, à altura do tratamento que acreditamos merecer por parte dos outros. E os perigos estão sempre à espreita, a qualquer momento uma casca de banana pode pôr a perder nossa compostura e dignidade com um tombo ridículo. Nesse sentido, Goffman afirma, analisando a introjeção desta forma de controle, que, na "prisão da vida social", cada pessoa é seu próprio algoz, "mesmo que alguns possam gostar de suas celas" (Idem, p. 10)

Essa forma de controle social perpassa todos os meandros de nossa vida cotidiana, apontando sobre cada pessoa uma "espada de Dâmocles" interacional. E, neste caso, qualquer pessoa indistintamente tem a possibilidade de, em algum momento, passar vergonha, seja por causa de uma gafe, seja por ser apanhada numa situação indevida. Esse tipo de coerção independe de uma força externa que nos obriga a agir de determinada maneira. Docilmente nos enquadramos, docilmente lemos os livros que todos lêem, docilmente aceitamos um ordenamento social freqüentemente injusto, desigual. Fazer frente a isso pode "pegar mal", pode "ficar chato", pode ser embaraçoso.

\section{Gênero e relações de poder}

Em Gender advertisements, Goffman, a partir de uma perspectiva etológica, analisa um conjunto de 508 anúncios publicitários publicados no início dos anos de 1970, explorando o modo como as imagens representam a relação entre homens e mulheres.

Para entender devidamente o quadro teórico goffmaniano nesta obra, alguns termos devem ser definidos a priori. $\mathrm{O}$ autor afirma que os anúncios 
publicitários "hiper-ritualizam" as relações de gênero. A idéia de "ritual" em Goffman refere-se a um comportamento expressivo, a gestos ou ações significativos. Por exemplo, meninos carregam seus cadernos ou livros debaixo do braço; meninas, em frente ao peito, com ambos os braços. Nada os impede ou os obriga a agirem assim, mas ter uma conduta que não se enquadra no que é considerado adequado a seu gênero pode gerar, por exemplo, dúvida sobre a masculinidade dos meninos ou a feminilidade das meninas. Trata-se de condutas "ritualizadas", portadoras de um sentido que não está, evidentemente, nas condutas em si, mas nos códigos culturais que nelas imprimem significado. Goffman chama estas - e outras - condutas de "rituais da interação", maneiras codificadas de comportamento expressivo, como saudações, pedidos de desculpa, ou mesmo ofensas deliberadas. Com relação aos papéis de gênero, Goffman usa uma noção fundamental, denominada gender display, ou "display de gênero". O termo display é oriundo da etologia, ramo da biologia que estuda o comportamento dos animais. Um display é a maneira pela qual um animal evidencia a outros o seu alinhamento a uma determinada situação. Por exemplo, se uma pessoa entrar em um pátio guardado por um cão, é possível que ele se coloque na sua frente, erice os pêlos, baixe as orelhas, rosne e mostre os dentes, mostrando que atacará o intruso caso ele dê mais um passo. Se a pessoa for sensata, vai recuar lentamente. Assim, o cão evita os riscos de efetivamente se envolver em uma luta que poderá causar danos a ele. Display é, portanto, uma forma de comunicação animal. Os "displays de gênero", no caso dos seres humanos, funcionam como marcadores rituais de pertencimento a grupos de gênero, e em geral são assumidos tacitamente (apesar de serem culturalmente codificados e aprendidos quando da socialização das crianças).

As imagens publicitárias são "hiper-ritualizadas" porque, se na vida cotidiana, os comportamentos expressivos ocorrem espontaneamente, na publicidade eles são "ensaiados", produzidos, repetidos, até que exprimam com a máxima eficiência comunicacional o sentido desejado. Isso ocorre pela própria natureza do discurso publicitário, que não tem tempo nem dinheiro (e na mídia, tempo é dinheiro) para perder com ambigüidades - os significados precisam ser captados num relance. Assim, são produzidas centenas de fotografias para que $a$ melhor seja escolhida. Então, como diz Goffman, com sua tradicional ironia, o médico dos anúncios publicitários tem muito mais "cara de médico" do que os médicos de verdade, embora se trate de um ator fazendo o papel de médico - seu avental é mais branco, seu estetoscópio, mais brilhante, seu diploma é repleto de medalhinhas. A hiper-ritualização do discurso publicitário apresenta o mundo cotidiano em estado de graça.

Analisando mais de quinhentas fotografias de homens e mulheres em interação nos anúncios publicitários, Goffman encontra regularidades surpreendentes: quando alguém ensina alguma coisa à outra pessoa, é o homem que ensina a mulher, mesmo que seja um garoto de seis anos "ensinando" a professora a utilizar um novo produto. Quando alguém é mais alto, é o homem que ocupa a posição superior. A única exceção é quando o viés de classe se interpõe, de modo que a mulher de classe alta aparece num plano superior, com seus serviçais - garçons, jardineiros etc., - curvando-se perante a "patroa", o que evidencia hierarquias sociais ritualizadas e, porque não assumidas nem colocadas em discussão, apresentadas como parte da "natureza", como obviedades.

Uma categoria de ritualização de gênero que permanece intacta até hoje, mesmo passados trinta anos de ação intensa do movimento feminista, é o chamado "toque feminino", manifestado na posição das mãos das mulheres. Nos anúncios, homens empunham objetos, utilizando-os em sua função prática: pegam a caneta e escrevem, pegam o volante do carro e dirigem, pegam uma maçã e comem. As mulheres, não. Elas se limitam a "tocar" os objetos - ou partes de seu corpo - com as pontas dos dedos, como se os acariciassem, mas não atuam sobre o mundo com esses objetos. Tal representação da feminilidade sustenta uma relação de poder naturalizada, em que a mulher ocupa um lugar "naturalmente" subordinado, ela se torna "naturalmente" um ornamento, trata-se da "essência" da feminilidade. Esse discurso, que supostamente está veiculado para vender produtos, "vende" também relações de poder, que se apresentam como obviedades, como evidências, mas que fundamentam, reiteram e sustentam uma desigualdade fundamental. Assim, além das relações de gênero nos anúncios, constata-se também outra relação de poder, qual seja, o poder da publicidade para com a sociedade à qual ela se destina, o vínculo forte entre os meios de comunicação de massa e o campo social. 
$\mathrm{Na}$ medida em que tais relações são consideradas óbvias - quando na realidade elas absolutamente não são -, perpetua-se aí uma hegemonia. Não é à toa que esta suposta naturalidade se torna uma fonte de constrangimento social, por exemplo para um casal em que o homem é menor que a mulher, ou ganha menos do que ela etc.. Essa naturalização é, ela própria, uma relação de poder, que colaborará para a desmobilização do debate no campo social, deixando de problematizar uma profunda desigualdade de gênero.

\section{Para concluir}

A perspectiva de Goffman nos permite entender, em vez da relação entre burguesia e proletariado, as interações entre patrões e empregados em uma fábrica; em vez de uma luta de classes explícita, a relação entre uma dona de casa e sua empregada doméstica. Nesses silenciosos campos de batalha, onde a luta de classes ocorre na nossa frente, nós temos no quadro teórico de Goffman uma magnífica ferramenta para estudar as relações entre pessoas, que geralmente são bastante problemáticas, que raramente não envolvem uma relação de ascendência de poder ou de desigualdade. Creio que Goffman apresenta um sólido quadro de referência para pensarmos a ordem da interação em contextos institucionais, escolares, de trabalho, na mídia, na família e mesmo na política.

Nesse sentido, é interessante refletirmos sobre a dimensão interacional da política, de que a lei e o Estado são talvez a face mais visível. Quem mora em Brasília certamente sabe muito bem o quanto as leis são criadas entre cafezinhos, elevadores e bilhetinhos... $\mathrm{Na}$ Constituição está a letra fria da lei, mas as palavras que as expressam são definidas com acordos fundados na ordem da interação, entre pares, em conversas que acabarão resultando na configuração mais explícita do poder. Com a perspectiva de Goffman, temos uma ferramenta teórica poderosa e ainda parcialmente inexplorada.

\section{BIBLIOGRAFIA}

BECKER, Howard. (2004), "As políticas da apresentação: Goffman e as instituições totais", in E. Gastaldo (org.), Erving Goffman, desbravador do cotidiano, Porto Alegre, Tomo Editorial.
CARLIN, Andrew. (2004), “'Enquadrando’ bibliografias: reflexividade, relevância e a 'imaginação sociológica"', in E. Gastaldo (org.), Erving Goffman, desbravador do cotidiano, Porto Alegre, Tomo Editorial.

DURKHEIM, Émile. (2002), As regras do método sociológico. São Paulo, Martins Fontes.

GASTALDO, E. (org.). (2004), Erving Goffman, desbravador do cotidiano. Porto Alegre, Tomo Editorial.

GOFFMAN, Erving. (1959), The presentation of self in everyday life. Garden City, NY, Doubleday. . (1967), Interaction ritual. Garden City, NY, Doubleday. . (1974), Manicômios, prisões e conventos. São Paulo, Perspectiva. (1975), A representação do eu na vida cotidiana. Petrópolis, Vozes.

(1975), Estigma: notas sobre a manipulação da identidade deteriorada. Rio de Janeiro, Zahar.

- (1979), Gender advertisements. Nova York, Harper and Row.

RIBEIRO, Branca \& GARCEZ, Pedro (org.). (1998), Sociolingüistica interacional. Porto Alegre, Age.

RILEY, Matilda \& NELSON, Edward (orgs.). (1976), A observação sociológica. Rio de Janeiro, Zahar.

VELHO, Gilberto. (2004), "Becker, Goffman e a antropologia no Brasil", in E. Gastaldo (org.), Erving Goffman, desbravador do cotidiano, Porto Alegre, Tomo Editorial.

WINKIN, Yves. (1998), Os momentos e seus homens. Lisboa, Relógio D’Água. 


\section{GOFFMAN E AS \\ RELAÇÕES DE PODER \\ NA VIDA COTIDIANA}

\author{
Édison Gastaldo
}

Palavras-chave: Erving Goffman; Poder; Cotidiano.

Este artigo busca explorar parte da obra do sociólogo canadense Erving Goffman, a propósito do tratamento dado por este autor acerca das relações de poder na vida cotidiana. Esse tema encontra-se difuso ao longo de toda a obra de Goffman, e evidencia uma perspectiva política da ordem da interação social. Analiso particularmente os livros The presentation of self in everyday life, de 1959, e Gender advertisements, de 1979, abordando temas como "definição de situação", "coerção social", "gênero" e "mídia".

\section{GOFFMAN AND THE \\ RELATIONS OF POWER IN THE DAILY LIFE}

\author{
Édison Gastaldo
}

Keywords: Erving Goffman; Poder; Everyday.

This paper aims at exploring part of the work of the Canadian sociologist Erving Goffman, especially his dealing with the relations of power in the daily life. This theme is diffusely found all around his work, thus highlighting a political perspective of the social interaction order. Two books are particularly analyzed: The presentation of self in everyday life (1959) and Gender advertisements (1979), where themes such as "status definition," "social coercion," "gender," and "media" are therefore approached.

\section{GOFFMAN ET LES \\ RELATIONS DE POUVOIR DANS LA VIE QUOTIDIENNE}

Édison Gastaldo

Mots-clés: Erving Goffman ; Pouvoir ; Quotidien.

Cet article se propose d'explorer l'œuvre du sociologue canadien Erving Goffman par rapport à l'abordage qu'il propose sur les relations de pouvoir dans la vie quotidienne. Ce thème se trouve dispersé tout au long de l'ensemble de l'œuvre de Goffman et met en évidence une perspective politique de l'ordre de l'interactivité sociale. J'analyse, particulièrement, les livres The presentation of self in everyday life, de 1959, et Gender advertisements, de 1979 , en abordant des thèmes tels la "définition de situation", la "contrainte sociale", le "genre" et les "médias". 